\title{
Treatment of Dye Wastewater Using Granular Activated Carbon and Zeolite Filter
}

\author{
Syafalni S. \\ School of Civil Engineering, Universiti Sains Malaysia \\ Engineering Campus, Seri Ampangan, Nibong Tebal 14300, Pulau Pinang, Malaysia \\ E-mail: cesyafalni@eng.usm.my \\ Ismail Abustan, Irvan Dahlan, \& Chan Kok Wah \\ School of Civil Engineering, Universiti Sains Malaysia \\ Engineering Campus, Seri Ampangan, Nibong Tebal 14300, Pulau Pinang, Malaysia
}

Genius Umar

Faculty of Agriculture, Cokroaminoto Palopo University, Indonesia

Received: December 1, 2011 Accepted: December 26, $2011 \quad$ Published: Feburary 1, 2012

doi:10.5539/mas.v6n2p37

URL: http://dx.doi.org/10.5539/mas.v6n2p37

\begin{abstract}
Dye wastewater sample contains moderate concentration of chemical oxygen demand (COD), ammonia $\left(\mathrm{NH}_{3}\right)$ and color. This work evaluates the removal of COD, ammonia and color in dye wastewater using granular activated carbon (GAC) and zeolite in the column studies. Different surface loading rates, height of adsorbent and empty bed contact time were used to investigate the efficiency of the adsorption process. The maximum removal efficiency was found at the surface loading rate of $2.84 \mathrm{ml} / \mathrm{cm}^{2}$.min and bed height of $10 \mathrm{~cm}$. Due to the characteristics of GAC and zeolite, a sequence of combination with both adsorbents produces a better removal of contaminants. The best removal of the contaminants among the all adsorption treatment was found using GAC (bottom layer) and zeolite (upper layer) in $6.35 \mathrm{~cm}$ diameter column with $59.46 \%$ removal of COD, $60.82 \%$ removal of ammonia and $58.4 \%$ removal of color. For the adsorption with zeolite as the bottom layer and GAC as the upper layer, the data fitted well with the Langmuir model. While for the adsorption with zeolite as the upper layer and GAC as the bottom layer, the data fitted well for both Langmuir and Freundlich isotherms.
\end{abstract}

Keywords: Dye wastewater, Granular activated carbon (GAC), Zeolite, Adsorption, Isotherm model

\section{Introduction}

Textile dyeing is one of the important industries in Malaysia. Different steps in the dyeing and finishing processes in textile dyeing industry, however, results in the generation of large quantities of colored dye wastewater (Babu, et al., 2007). The release of untreated colored wastewaters into the ecosystem can be very damaging to the receiving water bodies. Typically, untreated dyes wastewaters from dyestuff production and dyeing industries have a great variety of colors and difficult to biodegrade due to complex chemical structures. Furthermore, dyes used in the textile industry may be toxic to aquatic organisms and some of these dyes are suspected carcinogens (Erdem, et al., 2005; Hameed, 2009a; Pinheiro, et al., 2004; Babu, et al., 2007).

The environmental concern of these untreated dyes wastewaters has drawn the awareness of many research studies. Accordingly, various treatment processes have been employed for the removal of dyes from wastewater, such as coagulation/ flocculation process (Butt, et al., 2005), cation exchange membranes (Wu, et al., 2008), electrochemical degradation (Fan, et al., 2008), advanced oxidative process (Banerjee, et al., 2007; Mahmoud, et al., 2007; Fathima, et al., 2008), Fenton-biological treatment (Lodha, \& Chaudhari, 2007; Garcia-Montano, et al., 2008), and adsorption (Allen, et al., 2004; Erdem, et al., 2005; Hameed, 2009a; Hameed, et al., 2009).

Until now, adsorption technique using many types of adsorbents is still the most favorable method in the removal of contaminants from wastewaters due to its efficiency; high adsorption capacity and low operational 
cost method. Adsorbent such as activated carbon is very suitable for reducing the organic substances (such as COD/BOD) and color (Alvares, et al., 2001; Kalderis, et al., 2008; Ahmad, et al., 2009). On the other hands, zeolite was found very effective in reducing ammoniacal nitrogen and COD (Lee, et al., 1996; Chang, et al., 2001; Jung, et al., 2004; Otal, et al., 2005) since it have high cationic exchange capacities, large surface areas and high residual carbon contents.

The purpose of the present work was to evaluate the removal efficiency of ammonia, COD and color in dye wastewater using granular activated carbon (GAC) and zeolite, as well as to compare the performance of the sequence arrangement between GAC and zeolite as filter media in different surface diameter of column sizes. Apart from that, adsorption isotherms were also analyzed using equilibrium data for the combination of GAC and zeolite at different sequences.

\section{Materials and Methods}

\subsection{Materials}

The dye wastewater was taken from Penfabric Mill 3, Bayan Lepas, Penang. The dye wastewater mainly consists of dying ingredients, sodium sulphate anhydride $\left(\mathrm{Na}_{2} \mathrm{SO}_{4}\right)$ and PVA (polyvinyl alcohol). Table 1 presents the characteristics of the raw dye wastewater sample. Granular activated carbon (GAC) and zeolite were used as the media treatment (adsorbent) for dye wastewater. GAC and zeolite were supplied by Fudojaya Sdn. Bhd. GAC and zeolite were sieved to obtain the required particle size range of $1.18 \mathrm{~mm}-2.00 \mathrm{~mm}$. Zeolite was immersed into 1 $\mathrm{M}$ of $\mathrm{NaCl}$ for $24 \mathrm{~h}$ (Ilyas, 2007). Both adsorbents were rinsed with distilled water for several times to remove dust and others impurities. After that, both adsorbents were then placed in an oven at $105{ }^{\circ} \mathrm{C}$ for $24 \mathrm{~h}$ and subsequently dried in a desiccator for $2 \mathrm{~h}$ and it was ready to use.

\subsection{Analytical Methods}

The concentration of COD, ammoniacal nitrogen, and color were analyzed in accordance with the Standard Methods for the Examination of Water and Wastewater (APHA, 1992). Calorimetric method with $\mathrm{HACH}$ $\mathrm{DR} / 2010$ spectrometer (set at $620 \mathrm{~nm}$ wavelength) was used in measuring COD concentration. Ammonia concentrations was measured by Nesslerization Method $\left(4500 \mathrm{NH}_{3}\right)$ using a HACH DR/2010 spectrometer (set at $425 \mathrm{~nm}$ wavelength). While color was measured by APHA Platinum-Cobalt Method using HACH DR/2010 spectrometer (set at $455 \mathrm{~nm}$ wavelength) and distilled water was used as a blank. The unit that used for the color test is platinum cobalt (PtCo).

\subsection{Laboratory Column Studies}

The removal efficiency of COD, ammonia and color from dye wastewater was investigated using laboratory plastic column filled with GAC and zeolite. In this study, four set of experiments (shown in Figure 1 and Table 2) were conducted to determine the effectiveness of the adsorbents and it consists of column with surface diameter of $1.91 \mathrm{~cm}, 3.81 \mathrm{~cm}$ and $6.35 \mathrm{~cm}$, respectively. Columns were mounted vertically and the adsorbent (bed height of 6 $\mathrm{cm}, 8 \mathrm{~cm}$ and $10 \mathrm{~cm}$ ) was supported on a perforated net. A total sample of $500 \mathrm{ml}$ dye wastewater was used/prepared and drained from the holding tank to the specific flow rate using a control valve. The operation was down plug flow mode. Effluent samples were collected into a beaker after the adsorption treatment. All the sorption experiments were carried out at room temperature.

\subsection{Surface Loading Rate (SLR) \& Empty Bed Contact Time (EBCT)}

Three different flow rates $(90 \mathrm{ml} / \mathrm{min}, 270 \mathrm{ml} / \mathrm{min}$ and $510 \mathrm{ml} / \mathrm{min}$ ) were used for column filled with GAC (Figure 1a). While for column filled with zeolite (Figure 1b) and columns with sequences arrangement of GAC and zeolite (Figures 1c \& 1d), the flow rate used was $90 \mathrm{ml} / \mathrm{min}$. The surface loading rate (SLR) was calculated by,

$$
\text { Surface Loading Rate }(\mathrm{SLR})=\frac{\text { Volumetric Flow Rate }(\mathrm{ml} / \mathrm{min})}{\text { Column Cross Sectional Area }\left(\mathrm{cm}^{2}\right)}
$$

The SLR calculated ranges from 2.84 to $178.95 \mathrm{ml} / \mathrm{cm}^{2}$. min. The void volume for GAC and zeolite was found to be $58 \%$ and $52 \%$, respectively through the column experiment. It means that empty bed contact time (EBCT) is about twice the true contact time between the fluid being treated and the GAC particles. The EBCT for GAC and zeolite can be calculated based on these void volume of the wastewater sample in the desired bed height and flow rate that are given by Eqs. (2) and (3), respectively.

$$
\mathrm{EBCT}_{\mathrm{GAC}}=\frac{\left(\frac{\pi \mathrm{D}^{2}}{4}\right) \times \text { bed height } \times 0.58 \times 60}{\text { Volumetric Flow Rate }}
$$




$$
\mathrm{EBCT}_{\text {zeolite }}=\frac{\left(\frac{\pi \mathrm{D}^{2}}{4}\right) \times \text { bed height } \times 0.52 \times 60}{\text { Volumetric Flow Rate }}
$$

While the EBCT for the sequences arrangement of GAC and zeolite will be the sum of both EBCT according to the bed height in the treatment.

\subsection{Isotherm Models}

Freundlich and Langmuir isotherm models were applied in this study to analyze adsorption capacity of GAC and zeolite. The Freundlich isotherm is based on an assumption of adsorption onto heterogeneous surfaces, multilayer adsorption which is different with the Langmuir isotherm that based on assumption of monolayer adsorption. Experiment was carried out with different arrangement of adsorbent sequence in order to differentiate the adsorption capacity. The experiment was conducted using the same length of adsorbent but varying the diameter of the surface column (from $1.91 \mathrm{~cm}$ to $6.35 \mathrm{~cm}$ ). The dye wastewater was treated at the maximum condition (flow rate of $90 \mathrm{ml} / \mathrm{min}$ and bed height of $10 \mathrm{~cm}$ ). The amount of adsorption at equilibrium, $q_{e}(\mathrm{mg} / \mathrm{g}$ ), was calculated by the following equation,

$$
q_{e}=\frac{\left(C_{o}-C_{e}\right) \cdot V}{W}
$$

where $\mathrm{C}_{\mathrm{o}}$ and $\mathrm{C}_{\mathrm{e}}(\mathrm{mg} / \mathrm{L})$ are the liquid-phase concentrations of sample at initial and equilibrium, respectively. W $(\mathrm{g})$ is the mass of composite media used and $\mathrm{V}(\mathrm{L})$ is the volume of the solution. The removal efficiency of parameters studied can be calculated as follows,

$$
\text { Removal Efficiency }(\%)=\frac{C_{o}-C_{e}}{C_{o}} \times 100
$$

Adsorption isotherm is fundamentally essential to explain how solutes interact with adsorbents, and is critical in optimizing the use of adsorbents (Hameed, 2009b). The Langmuir (Langmuir, 1916) and the Freundlich (Freundlich, 1906) were employed in the present study. The linearized forms of the two isotherms are as follows,

$$
\begin{aligned}
& \frac{1}{q_{e}}=\frac{1}{K_{a} q_{m} C_{e}}+\frac{1}{q_{m}} \\
& \ln q_{e}=\ln K_{F}+\frac{1}{n} \ln C_{e}
\end{aligned}
$$

The Langmuir constants, $q_{m}(\mathrm{mg} / \mathrm{g})$ and $\mathrm{K}_{\mathrm{a}}(\mathrm{L} / \mathrm{mg})$, are related to adsorption capacity and energy of adsorption, respectively. While $\mathrm{K}_{\mathrm{F}}$ and $n$ are Freundlich constants.

\subsection{Data Precision}

Every analysis and experimental run was repeated at least two to three times to increase the precision of the results, and only the average value was reported throughout this study. The repeatability of the experimental data was found to be sufficiently high with relative error between repeated runs less than $5 \%$.

\section{Results and Discussion}

\subsection{Effects of SLR on the GAC and Zeolite Adsorption Processes}

The effect of SLR on the removal of COD, ammonia and color using GAC adsorbent are shown in Figures 2 to 4 at various surface diameter and bed height. It can be seen from these figures the maximum reduction for all parameters were recorded at $10 \mathrm{~cm}$ of GAC height and SLR of $31.58 \mathrm{ml} / \mathrm{cm}^{2} . \mathrm{min}, 7.89 \mathrm{ml} / \mathrm{cm}^{2} . \mathrm{min}$, and 2.84 $\mathrm{ml} / \mathrm{cm}^{2}$.min. The maximum COD reductions for surface column diameter of $1.91 \mathrm{~cm}, 3.81 \mathrm{~cm}$ and $6.35 \mathrm{~cm}$ were $11.88 \%, 28.89 \%$ and $40.31 \%$, respectively. For ammonia, the maximum reduction of $12.08 \%, 27.03 \%$ and $40.79 \%$ were obtained at surface column diameter of $1.91 \mathrm{~cm}, 3.81 \mathrm{~cm}$ and $6.35 \mathrm{~cm}$, respectively. The same trend was also observed for color removal. The adsorption rate is controlled by two intraparticle diffusion mechanisms, i.e. diffusion within the pore volume (pore diffusion) and diffusion along the surface of pores (surface diffusion) (Tien, 1994). Adsorption at low SLR may provide more adequate contact time for impurity to transport from liquid to the pores of adsorbent. Based on this result, it can be concluded that higher removal of COD, ammonia and color could be obtained at a lower SLR and higher bed of GAC adsorbent. The maximum removal condition for all the parameters using GAC was obtained at SLR of $2.84 \mathrm{ml} / \mathrm{cm}^{2} . \mathrm{min}$ and adsorbent height of $10 \mathrm{~cm}$.

On the other hand, the effect of various SLR and bed height on the removal of COD, ammonia and color using zeolite adsorbent are shown in Figure 5. It was shown that the removal percentage for all parameters increase with 
increasing the height of zeolite column and decreasing the SLR values. The maximum COD, ammonia and color reduction of $20.53 \%, 45.62 \%$ and $39.86 \%$, respectively were obtained using $10 \mathrm{~cm}$ zeolite height and SLR of 2.84 $\mathrm{ml} / \mathrm{cm}^{2} . \mathrm{min}$. The increase in the removal percentage for all parameters leads to decrease in the solute concentration in the effluent. Consequently, the effluent concentration might be reduced with further increase in the bed height of zeolite.

\subsection{Effects of EBCT on the GAC and Zeolite Adsorption Processes}

Figure 6 depicts the effect of contact time (EBCT) on the removal of COD, ammonia and color at various GAC heights. The contact times used were varied (ranges from $7-123$ seconds) by the increment of the surface diameter of the column from $1.91 \mathrm{~cm}$ to $6.35 \mathrm{~cm}$, depending on the total volume of GAC used. When the adsorption process was carried out at $6 \mathrm{~cm}$ GAC height (Figure 6a), the reduction of COD, ammonia and color was only about $5.28 \%, 5.42 \%$ and $16 \%$, respectively at lower contact time. However, the amount of all parameters adsorbed increases with time and reaches a constant value after $20 \mathrm{~s}$. After the equilibrium time, the amount of all parameters adsorbed did not alter with time. However, when GAC column was filled with higher bed, especially with $10 \mathrm{~cm}$ bed height, different results were obtained. It was shown that the removal percentage for all parameters increase with increasing the contact time between dye and GAC. Eventually, a saturation curves were not reached in all curves of Figures $6 \mathrm{~b}$ and $6 \mathrm{c}$ (except COD reduction curve in Figure 6b) indicating that the adsorbent was not saturated in this level of contact time studied. From the figures, it was observed that the maximum removal was found to be at $123 \mathrm{~s}$ (Figure $6 \mathrm{c}$ ) with a total of $40.31 \%, 40.79 \%$ and $49.46 \%$ reduction of COD, ammonia and color, respectively.

At the same time, the experiment was also carried out to study the effect of contact time (EBCT) on the removal of COD, ammonia and color using various heights of zeolite. It was observed from Figure 7 that the maximum removal for all parameters was found at the maximum contact time. This indicates that higher contact time between dye and zeolite will lead to higher removal efficiency till the equilibrium time is reached. From the Figures, it was observed that the maximum removal was found to be at $110 \mathrm{~s}$ using $10 \mathrm{~cm}$ height of zeolite.

\subsection{Effects of EBCT toward the Sequence Arrangement of GAC and Zeolite}

Sequence arrangement of activated carbon-zeolite formed by the zeolite growth on porous carbon supports can possess the bifunctional properties of both carbon and zeolite, which have the potential to remove the contaminants from dye wastewater (Zhang et al., 2004). In this study, the sequence arrangement of GAC and zeolite for dye wastewater treatment was carried out, whereby zeolite was filled at the lower part and GAC was filled at the upper part of the column and visa versa. It was found from Figure 8 that the removal percentage for all parameters increases with increasing the contact time for both sequence arrangements. The maximum reduction of COD, ammonia and color of $42.95 \%, 55.71 \%$ and 55.83, respectively were obtained using zeolite-GAC sequence arrangement with a total of $233 \mathrm{~s}$ of contact time. The result shows that the removal percentage for all parameters was increased as compared to the column filled with only GAC or zeolite.

\subsection{Adsorption Isotherm}

In this study, the Freundlich and Langmuir adsorption models, which have been successfully applied to many adsorption processes, were used to study the COD, ammonia, and color adsorption behaviour of GAC and zeolite combination. The Freundlich isotherm is based on an assumption of adsorption onto heterogeneous surfaces, multilayer adsorption which is different with the Langmuir isotherm that based on assumption of monolayer adsorption. The maximum performance of the media (SLR of $2.84 \mathrm{ml} / \mathrm{cm}^{2} . \mathrm{min}, 7.892 .84 \mathrm{ml} / \mathrm{cm}^{2} . \mathrm{min}$ and 31.58 $2.84 \mathrm{ml} / \mathrm{cm}^{2} . \mathrm{min}$; adsorbent height of $10 \mathrm{~cm}$ for each GAC and zeolite) was chosen in order to compare the effectiveness in changing the sequence of the adsorbents for every different surface diameter of surface columns.

\subsection{Freundlich Isotherm}

Figures 9 and 10 shows the linear plot ( $\ln$ qe versus $\ln C$ e) of Freundlich isotherm for zeolite-GAC and GAC-zeolite arrangements, respectively using experimental data obtained. The applicability of the model suggests multilayer of the adsorbate at the outer surface of the adsorbent is significant. Values of $K_{f}$ and $1 / n$ calculated from the plot shown in Figures 9 and 10 are listed in Table 3. From the isotherm above, the correlation coefficient $\left(\mathrm{R}^{2}\right)$ is in the range of 0.768 to 0.894 for zeolite-GAC arrangement. Whereas for GAC-zeolite arrangement, high $\mathrm{R}^{2}$ values of 0.984 and 0.992 , respectively were obtained for COD and color removal. On the other hand, the $\mathrm{R}^{2}$ for ammonia is only $0.756 . \mathrm{K}_{\mathrm{f}}$ value shows the combination of both adsorbents represents beneficial adsorption. Therefore, the adsorption (by both sequence arrangement) was favorable for COD, ammonia and color, whereby new adsorption sites are available and the adsorption capacity increases as the value of $1 / \mathrm{n}<1$. 


\subsection{Langmuir Isotherm}

The linear plot of specific adsorption (1/qe) against the equilibrium concentration $(1 / C \mathrm{e})$ (Figures 11 and 12) shows that the adsorption also obeys the Langmuir model. The Langmuir constants $q \mathrm{~m}$ and $K \mathrm{a}$ were determined from the slope and intercept of the plot and are presented in Table 4. The value of the coefficient of correlation $\left(R^{2}\right)$ range from 0.897 to 0.923 (for zeolite-GAC arrangement) and from 0.869 to 0.991 (for GAC-zeolite arrangement) obtained from Langmuir expression indicates that Langmuir expression provided a better fit to the experimental data.

Since the value of coefficient of determination $\left(\mathrm{R}^{2}\right)$ in Langmuir isotherm is almost the same with Freundlich isotherm in COD, ammonia and color removal for adsorption with GAC and zeolite, therefore, the results show the Langmuir isotherm is also fitted with the Freundlich model.

\section{Conclusion}

The treatment of dye wastewater using GAC and zeolite adsorbents was investigated under different experimental conditions in column process. The criteria of determining the reduction of contaminants are basically found that depend on the surface loading rate (SLR), bed depth of adsorbent, the empty bed contact time and the type of adsorbent used. The different in the length of adsorbent and surface diameter column will yield different contact time. In addition, the particle size of adsorbent will also affect the performance of adsorbent. Among the SLR that have been conducted in $1.91 \mathrm{~cm}, 3.81 \mathrm{~cm}$ and $6.35 \mathrm{~cm}$ diameter of surface column, the maximum SLR in removing contaminants was $2.84 \mathrm{ml} / \mathrm{min} . \mathrm{cm}^{2}$. The lower SLR and longer in adsorbent depth will increase the volume of adsorption process. The higher volume of the contact bed adsorbent yield the longer contact time and better removal will be produced. At the higher SLR will decrease the EBCT and lesser of contaminants will be adsorbed in GAC and zeolite. In relation to the characteristics of GAC and zeolite, a sequence of combination with both adsorbents may produce a better removal of contaminants. From the data that obtained, the arrangement of GAC as the bottom layer and zeolite as the upper layer produce better result in all parameters. The maximum removal of the contaminants among the all adsorption treatment was found using $10 \mathrm{~cm}$ of GAC (bottom layer) and $10 \mathrm{~cm}$ of zeolite (upper layer) in $6.35 \mathrm{~cm}$ diameter column with $59.46 \%$ removal of COD, $60.82 \%$ removal of ammonia and $58.4 \%$ removal of color. The Freundlich and Langmuir isotherm models were used to express the sorption phenomena of dye wastewater removal using sequence of combination of GAC and zeolite. Linear regression of the experimental data showed that the Freundlich and Langmuir isotherm models can be used to describe COD, ammonia and color removal.

\section{Acknowledgement}

The authors wish to acknowledge the financial support from the Ministry of Science, Technology and Innovation (MOSTI) Malaysia and Universiti Sains Malaysia (Short Term Grant).

\section{References}

Ahmad, A. A., \& Hameed, B. H. (2009). Reduction of COD and color of dyeing effluent from a cotton textile mill by adsorption onto bamboo-based activated carbon. Journal of Hazardous Materials, 172, 1538-1543. http://dx.doi.org/10.1016/j.jhazmat.2009.08.025

Allen, S. J., Mckay, G., \& Porter, J. F. (2004). Adsorption isotherm models for basic dye adsorption by peat in single and binary component systems. Journal of Colloid and Interface Science, 280, 322-333. http://dx.doi.org/10.1016/j.jcis.2004.08.078

Alvares, A. B. C, Diaper, C., \& Parsons, S. A. (2001). Partial oxidation of hydrolysed and unhydrolysed textile azo dyes by ozone and the effect on biodegradability. Process Safety and Environmental Protection, 79(2), 103-108. http://dx.doi.org/10.1205/09575820151095184

APHA. (1992). Standard Methods for the Examination of Water and Waste Water, 19th ed. American Public Health Association, Washington, D.C.

Babu, B. R., Parande, A. K., Raghu, S., \& Prem Kumar, T. (2007). Cotton textile processing: Waste generation and effluent treatment. Journal of Cotton Science, 11, 141-153.

Banerjee, P., Dasgupta, S., \& De, S. (2007). Removal of dye from aqueous solution using a combination of advanced oxidation process and nanofiltration. Journal of Hazardous Materials, 140, 95-103. http://dx.doi.org/10.1016/j.jhazmat.2006.06.075

Butt, M. T., Arif, F., Shafique, T., \& Imtiaz, N. (2005). Spectrophotometric estimation of colour in textile dyeing wastewater. Journal of the Chemical Society of Pakistan, 27(6), 627-630. 
Chang, W., Hong, S., \& Park, J. (2001). Effect of zeolite media for the treatment of textile wastewater in a biological aerated filter. Process Biochemistry, 37, 693-698. http://dx.doi.org/10.1016/S0032-9592(01)00258-8

Erdem, E., Çölgeçen, G., \& Donat, R. (2005). The removal of textile dyes by diatomite earth. Journal of Colloid and Interface Science, 282, 314-319. http://dx.doi.org/10.1016/j.jcis.2004.08.166

Fan, L., Zhou, Y., Yang, W., Chen, G., \& Yang, F. (2008). Electrochemical degradation of aqueous solution of Amaranth azo dye on ACF under potentiostatic model. Dyes Pigments, 76, 440-446. http://dx.doi.org/10.1016/j.dyepig.2006.09.013

Fathima, N. N., Aravindhan, R., Rao, J. R., \& Nair, B. U. (2008). Dye house wastewater treatment through advanced oxidation process using $\mathrm{Cu}$-exchanged $\mathrm{Y}$ zeolite: A heterogeneous catalytic approach. Chemosphere, 70, 1146-1151. http://dx.doi.org/10.1016/j.chemosphere.2007.07.033

Freundlich, H. M. F. (1906). Over the adsorption in solution. Journal of Physical Chemistry, 57, 385-470.

Garcia-Montano, J., Perez-Estrada, L., Oller, I., Maldonado, M. I., Torrades, F., \& Peral, J. (2008). Pilot plant scale reactive dyes degradation by solar photo-Fenton and biological processes. Journal of Photochemistry and Photobiology A: Chemistry, 195, 205-214. http://dx.doi.org/10.1016/j.jphotochem.2007.10.004

Hameed, B. H. (2009a). Spent tea leaves: A new non-conventional and low-cost adsorbent for removal of basic dye from aqueous solutions. Journal of Hazardous Materials, 161, 753-759. http://dx.doi.org/10.1016/j.jhazmat.2008.04.019

Hameed, B. H. (2009b). Evaluation of papaya seeds as a novel non-conventional low-cost adsorbent for removal of methylene blue. Journal of Hazardous Materials, 162, 939-944. http://dx.doi.org/10.1016/j.jhazmat.2008.05.120

Hameed, B. H., Krishni, R. R., \& Sata, S. A. (2009). A novel agricultural waste adsorbent for the removal of cationic dye from aqueous solutions. Journal of Hazardous Materials, 162, 305-311. http://dx.doi.org/10.1016/j.jhazmat.2008.05.036

Ilyas, H. (2007). Penyerapan besi dan ammonium dalam air oleh zeolite Lampung. MSc Thesis, Universitas Islam Negeri Syarif Hidayatullah, Jakarta.

Jung, J., Chung, Y. C., Shin, H. S., \& Son, D. H. (2004). Enhanced ammonia nitrogen removal using existent biological regeneration and ammonium exchange of zeolite in modified SBR process. Water Research, 38, 347-354. http://dx.doi.org/10.1016/j.watres.2003.09.025

Kalderis, D., Koutoulakis, D., Paraskeva, P., Diamadopoulos, E., Otal, E., del Valle, J. O., \& Fernández-Pereira, C. (2008). Adsorption of polluting substances on activated carbons prepared from rice husk and sugarcane bagasse. Chemical Engineering Journal, 144(1), 42-50. http://dx.doi.org/10.1016/j.cej.2008.01.007

Langmuir, I. (1916). The constitution and fundamental properties of solids and liquids, Part I. Solids. Journal of the American Chemical Society, 38(11), 2221-2295. http://dx.doi.org/10.1021/ja02268a002

Lee, J. H., Kim, D. S., Lee, S. O., \& Shin, B. S. (1996). Treatment of municipal landfill leachates using artificial zeolite. Chawon Risaikring, 5, 34-41.

Lodha, B., \& Chaudhari, S. (2007). Optimization of Fenton-biological treatment scheme for the treatment of aqueous dye solutions. Journal of Hazardous Materials, 148, 459-466. http://dx.doi.org/10.1016/j.jhazmat.2007.02.061

Mahmoud, A. S., Brooks, M. S., \& Ghaly, A. E. (2007). Decolorization of remazol brilliant blue dye effluent by advanced photo oxidation process $\left(\mathrm{H}_{2} \mathrm{O}_{2} / \mathrm{UV}\right.$ system). American Journal of Applied Sciences, 4(12), 1054-1062. http://dx.doi.org/10.3844/ajassp.2007.1054.1062

Otal, E., Vilches, L. F., Moreno, N., Querol, X., Vale, J., \& Fernández Pereira, C. (2005). Application of zeolitised coal fly ashes to the depuration of liquid wastes. Fuel, 84, 1440-1446. http://dx.doi.org/10.1016/j.fuel.2004.08.030

Pinheiro, H. M., Touraud, E., \& Thomas, O. (2004). Aromatic amines from azo dye reduction: status review with emphasis on direct UV spectrophotometric detection in textile industry wastewaters. Dyes and Pigments, 61, 121-139. http://dx.doi.org/10.1016/j.dyepig.2003.10.009

Tien, C. (1994). Adsorption Calculations and Modeling. Butterworth-Heinemann, Boston

Wu, J. S., Liu, C. H., Chu, K. H., \& Suen, S. Y. (2008). Removal of cationic dye methyl violet 2B from water by cation exchange membranes. Journal of Membrane Science, 309, 239-245. http://dx.doi.org/10.1016/j.memsci.2007.10.035

Zhang, X., Zhu, W., Liu, H., \& Wang, T. (2004). Novel tubular composite carbon-zeolite membranes. Material Letters, 58, 2223-2226. http://dx.doi.org/10.1016/j.matlet.2004.01.027 
Table 1. Characteristics of the raw dye wastewater

\begin{tabular}{|l|l|l|}
\hline Parameter & Unit & Average Value \\
\hline $\mathrm{pH}$ & - & $9.0-10.18$ \\
\hline Turbidity & $\mathrm{FAU}$ & $63-74$ \\
\hline COD & $\mathrm{mg} / \mathrm{L}$ & $298-360$ \\
\hline Suspended solid & $\mathrm{mg} / \mathrm{L}$ & 0.0076 \\
\hline Zinc & $\mathrm{mg} / \mathrm{L}$ & $<0.2$ \\
\hline Manganese & $\mathrm{mg} / \mathrm{L}$ & $0.5-0.6$ \\
\hline Iron & $\mathrm{mg} / \mathrm{L}$ & $0.13-0.15$ \\
\hline Copper & $\mathrm{mg} / \mathrm{L}$ & 0.03 \\
\hline Ammonia & $\mathrm{mg} / \mathrm{L}$ & $2.10-3.8$ \\
\hline True Color & $\mathrm{PtCo}$ & $680-750$ \\
\hline
\end{tabular}

Table 2. The arrangement of the experiment studies

\begin{tabular}{|l|l|l|}
\hline Experiment & Bottom Layer & Upper Layer \\
\hline Experiment 1 & GAC & \\
\hline Experiment 2 & Zeolite & \\
\hline Experiment 3 & Zeolite & GAC \\
\hline Experiment 4 & GAC & Zeolite \\
\hline
\end{tabular}

Table 3. Freundlich isotherm for COD, ammonia and color removal

\begin{tabular}{|l|l|l|l|}
\hline Parameters & COD & Ammonia & Color \\
\hline Zeolite-GAC arrangement: & & \\
\hline $\mathrm{R}^{2}$ & 0.894 & 0.768 & 0.793 \\
\hline $\mathrm{K}_{\mathrm{f}}$ & $1.293 \times 10^{-9}$ & $6.382 \times 10^{-6}$ & $2.862 \times 10^{-11}$ \\
\hline $1 / \mathrm{n}$ & 0.383 & 0.336 & 0.310 \\
\hline Freundlich & $\mathrm{q}_{\mathrm{e}}=1.293 \times 10^{-9} \mathrm{C}_{\mathrm{e}}^{0.383}$ & $\mathrm{q}_{\mathrm{e}}=6.382 \times 10^{-6} \mathrm{C}_{\mathrm{e}}^{0.336}$ & $\mathrm{q}_{\mathrm{e}}=2.862 \times 10^{-11} \mathrm{C}_{\mathrm{e}} 0.310$ \\
\hline equation & & & \\
\hline & & & \\
\hline GAC-Zeolite arrangement: & & \\
\hline $\mathrm{R}^{2}$ & 0.984 & 0.756 & 0.992 \\
\hline $\mathrm{K}_{\mathrm{f}}$ & $3.171 \times 10^{-7}$ & $6.866 \times 10^{-6}$ & $3.124 \times 10^{-11}$ \\
\hline $1 / \mathrm{n}$ & 0.641 & 0.425 & 0.269 \\
\hline Freundlich & $\mathrm{q}_{\mathrm{e}}=3.171 \times 10^{-7} \mathrm{C}_{\mathrm{e}}^{0.641}$ & $\mathrm{q}_{\mathrm{e}}=6.866 \times 10^{-6} \mathrm{C}_{\mathrm{e}}^{0.425}$ & $\mathrm{q}_{\mathrm{e}}=3.124 \times 10^{-11} \mathrm{C}_{\mathrm{e}}^{0.269}$ \\
\hline equation & & & \\
\hline
\end{tabular}


Table 4. Langmuir isotherm for COD, ammonia and color removal

\begin{tabular}{|c|c|c|c|}
\hline Parameters & COD & Ammonia & Color \\
\hline \multicolumn{4}{|c|}{ Zeolite-GAC arrangement: } \\
\hline $\mathrm{R}^{2}$ & 0.923 & 0.897 & 0.911 \\
\hline $\mathrm{K}_{\mathrm{a}}(\mathrm{L} / \mathrm{g})$ & -0.264 & -0.750 & -0.003 \\
\hline$q_{m}(\mathrm{mg} / \mathrm{g})$ & $-1.54 \times 10^{-3}$ & $-1.89 \times 10^{-6}$ & $-4.28 \times 10^{-4}$ \\
\hline $\begin{array}{l}\text { Langmuir } \\
\text { Equation }\end{array}$ & $\mathrm{q}=\frac{4.066 \times 10^{-4} C_{e}}{1-0.264 C_{e}}$ & $\mathrm{q}=\frac{1.418 \times 10^{-6} C_{e}}{1-0.750 C_{e}}$ & $\mathrm{q}=\frac{1.284 \times 10^{-6} C_{e}}{1-0.003 C_{e}}$ \\
\hline \multicolumn{4}{|c|}{ GAC-Zeolite arrangement: } \\
\hline $\mathrm{R}^{2}$ & 0.976 & 0.869 & 0.991 \\
\hline $\mathrm{K}_{\mathrm{a}}(\mathrm{L} / \mathrm{g})$ & 0.0043 & 0.6494 & 0.00369 \\
\hline$q_{m}(\mathrm{mg} / \mathrm{g})$ & $5.4 \times 10^{-4}$ & $3.2 \times 10^{-6}$ & $3.3 \times 10^{-4}$ \\
\hline $\begin{array}{l}\text { Langmuir } \\
\text { Equation }\end{array}$ & $\mathrm{q}=\frac{2.322 \times 10^{-6} C_{e}}{1-0.0043 C_{e}}$ & $\mathrm{q}=\frac{2.078 \times 10^{-6} C_{e}}{1-0.6494 C_{e}}$ & $\mathrm{q}=\frac{1.218 \times 10^{-6} C_{e}}{1-0.00369 C_{e}}$ \\
\hline
\end{tabular}




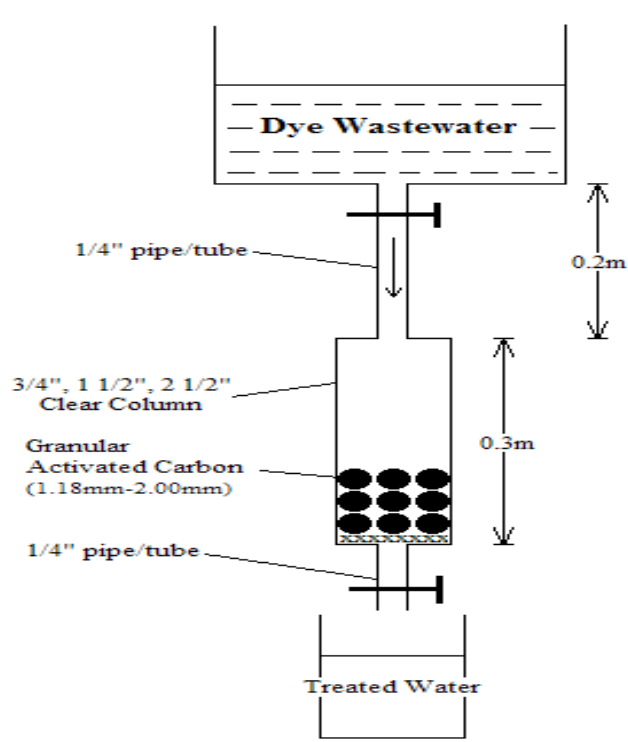

(a)

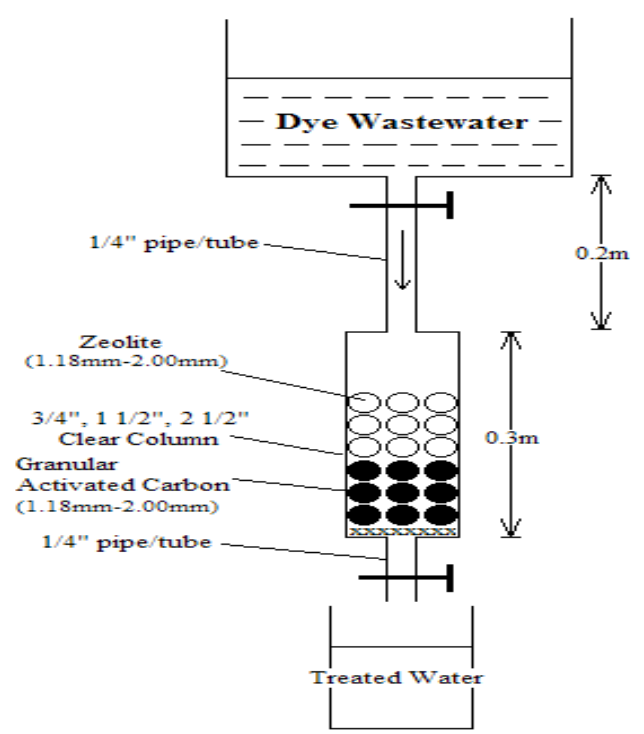

(c)

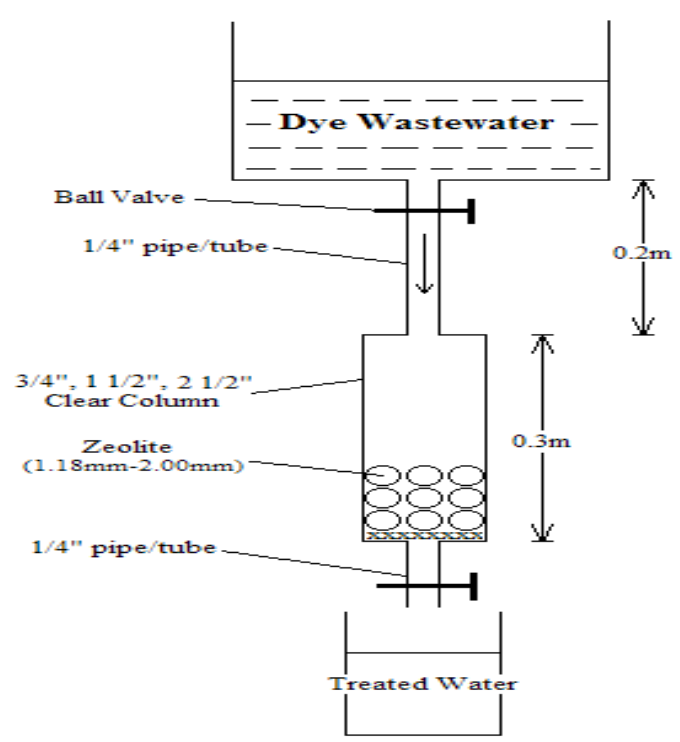

(b)

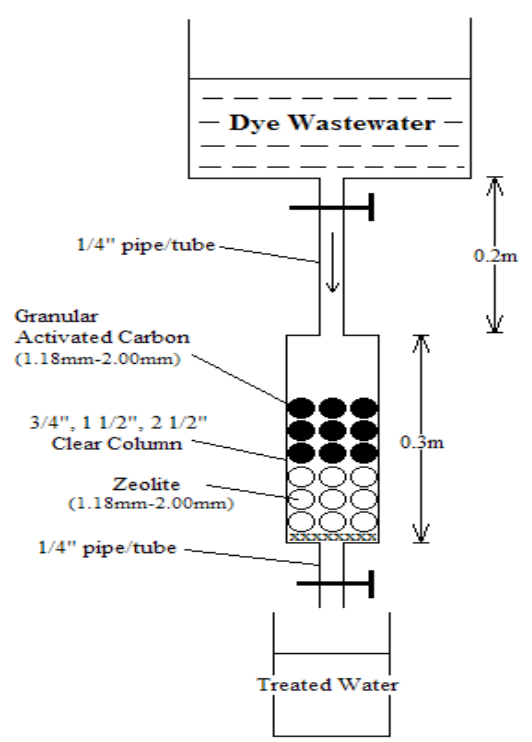

(d)

Figure 1. Column studies 


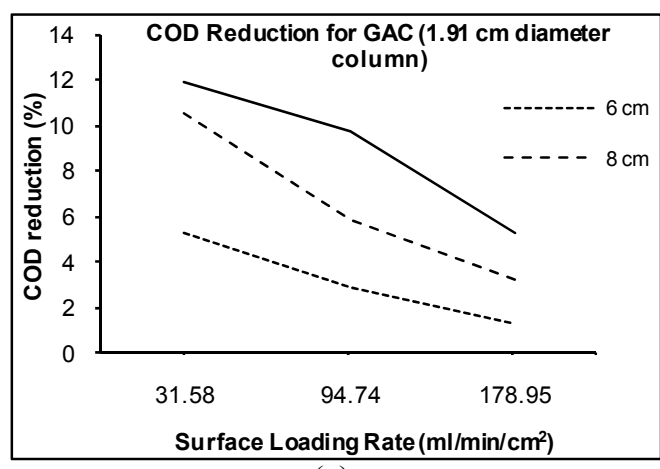

(a)

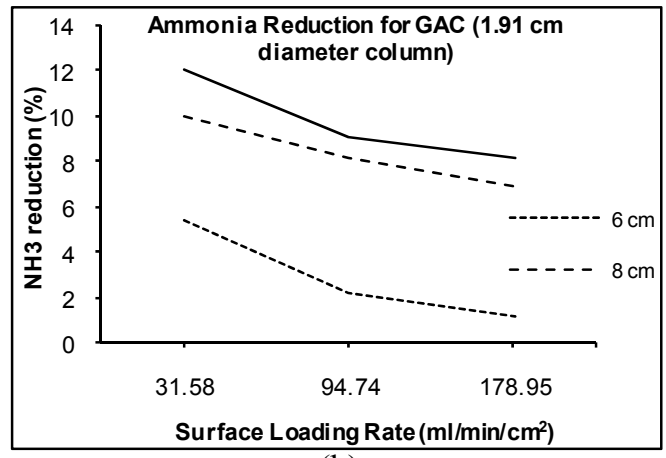

(b)

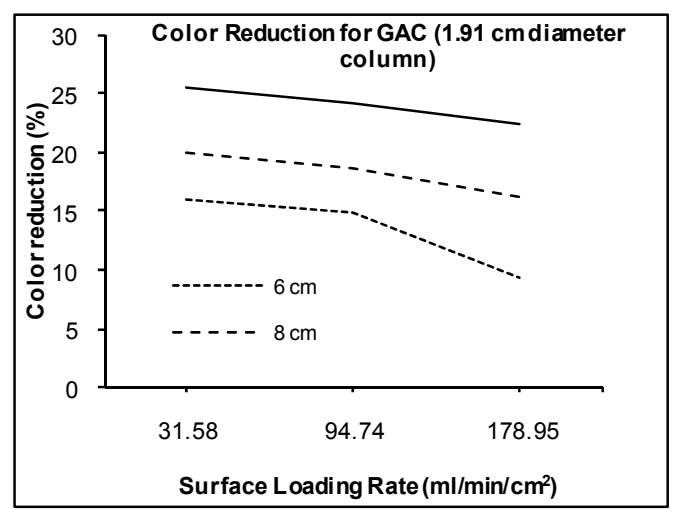

(c)

Figure 2. Removal efficiency of (a) COD, (b) ammonia and (c) color in dye wastewater using GAC column (with surface diameter of $1.91 \mathrm{~cm}$ ) at different SLR and bed height

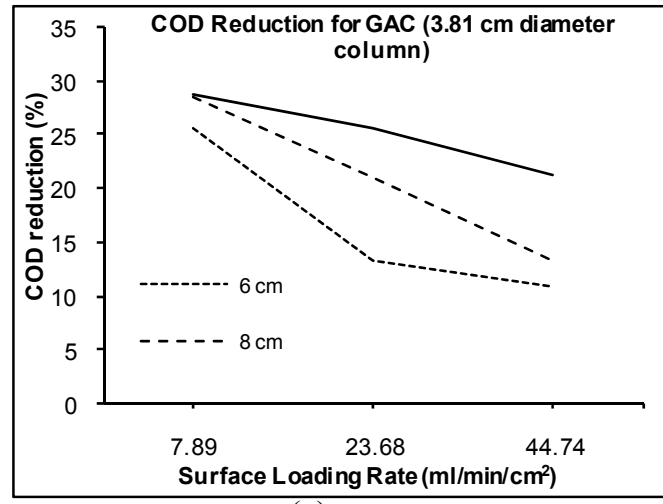

(a)

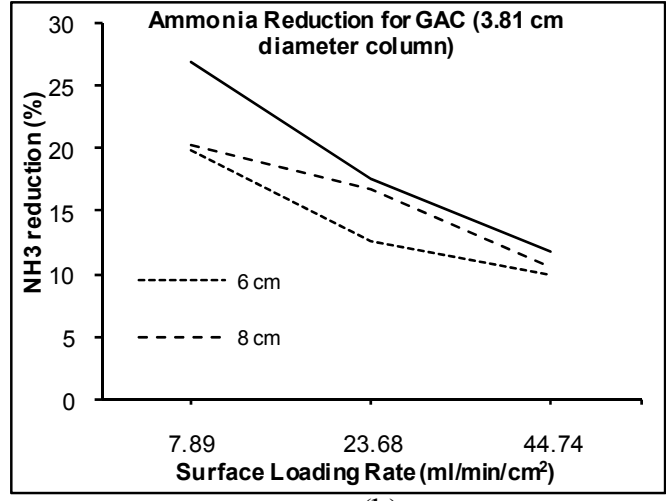

(b)

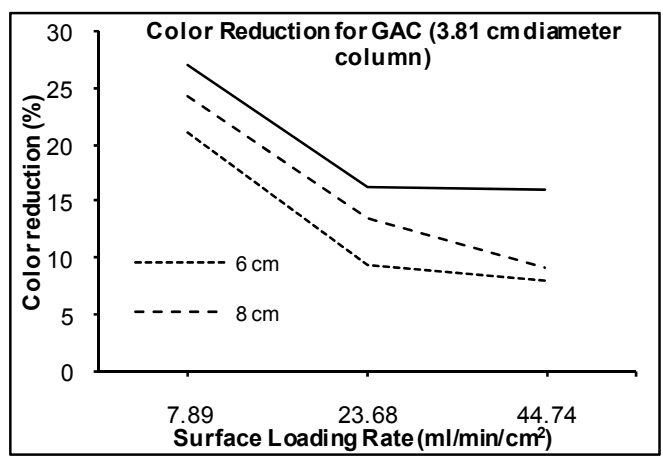

(c)

Figure 3. Removal efficiency of (a) COD, (b) ammonia and (c) color in dye wastewater using GAC column (with surface diameter of $3.81 \mathrm{~cm}$ ) at different SLR and bed height 


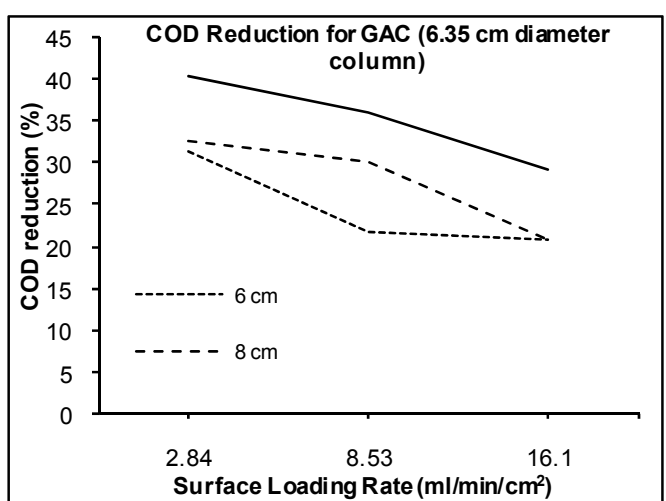

(a)

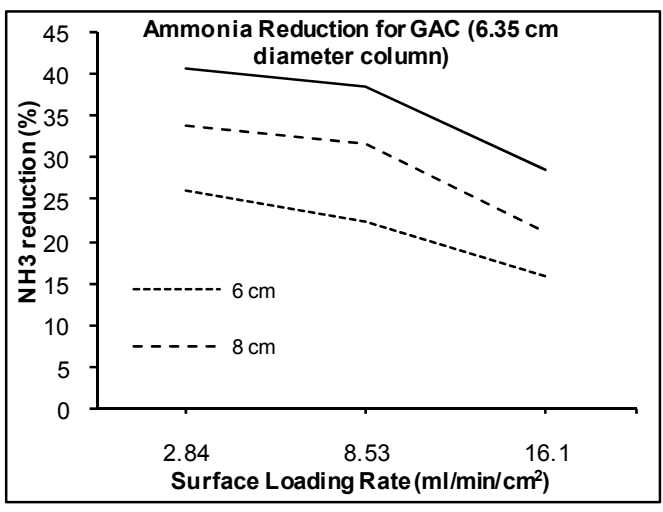

(b)

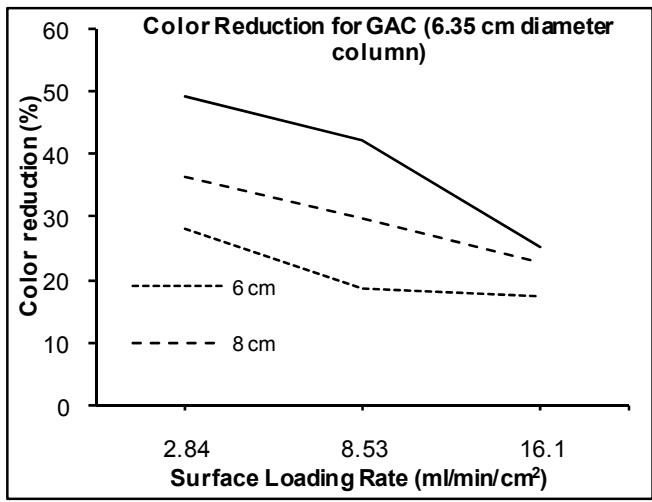

(c)

Figure 4. Removal efficiency of (a) COD, (b) ammonia and (c) color in dye wastewater using GAC column (with surface diameter of $6.35 \mathrm{~cm}$ ) at different SLR and bed height

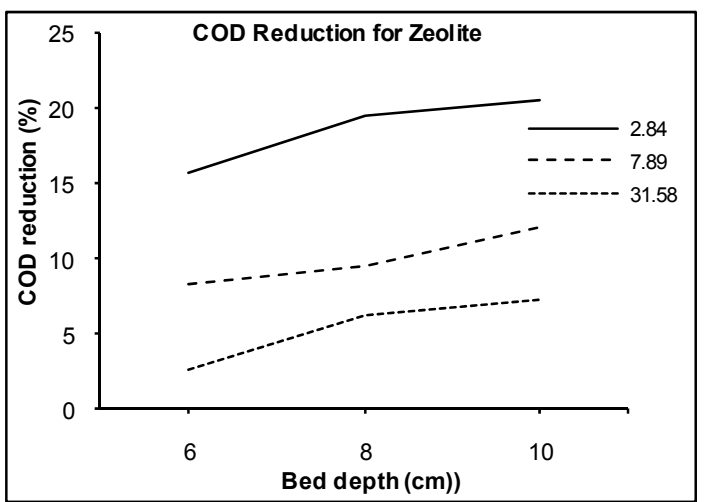

(a)

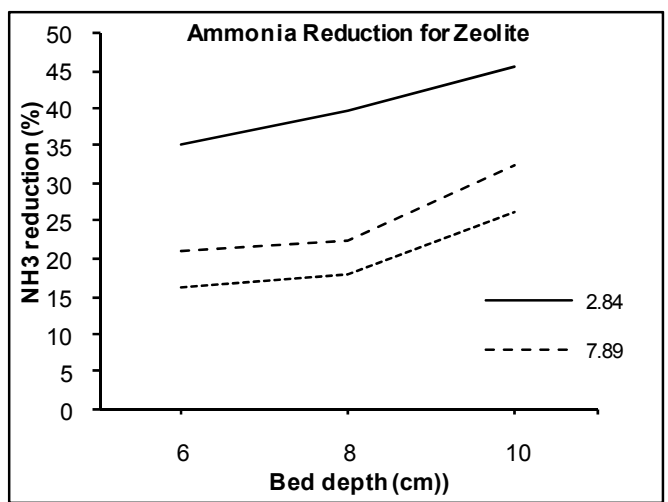

(b)

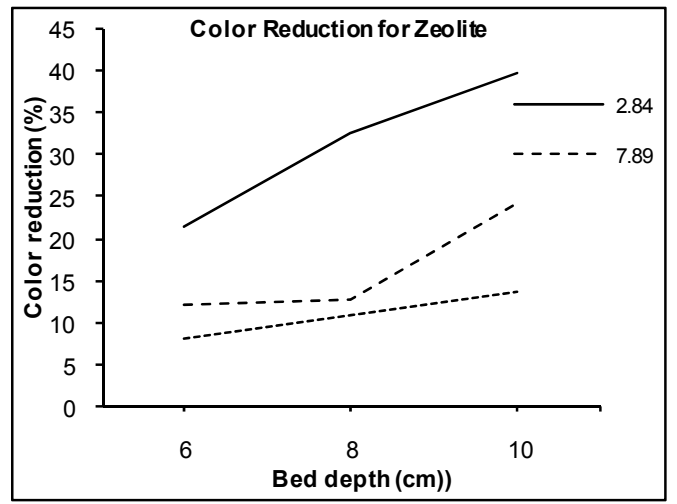

(c)

Figure 5. Removal efficiency of (a) COD, (b) ammonia and (c) color in dye wastewater using zeolite column (with surface diameter of $1.91 \mathrm{~cm}$ ) at different SLR and bed height 


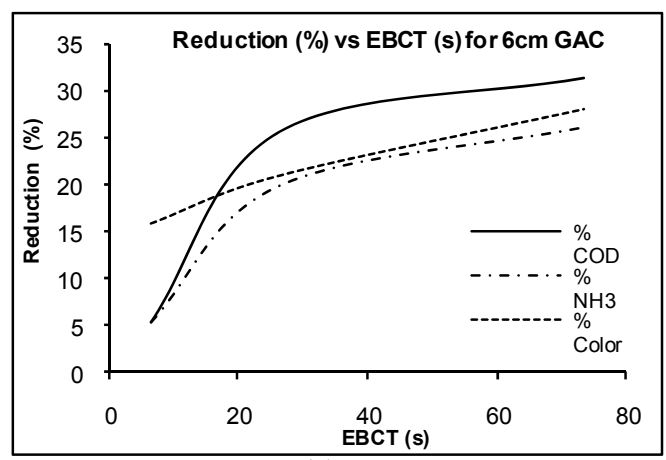

(a)

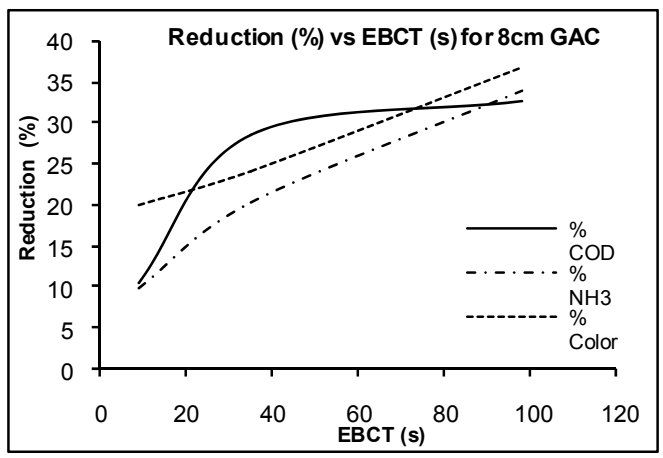

(b)

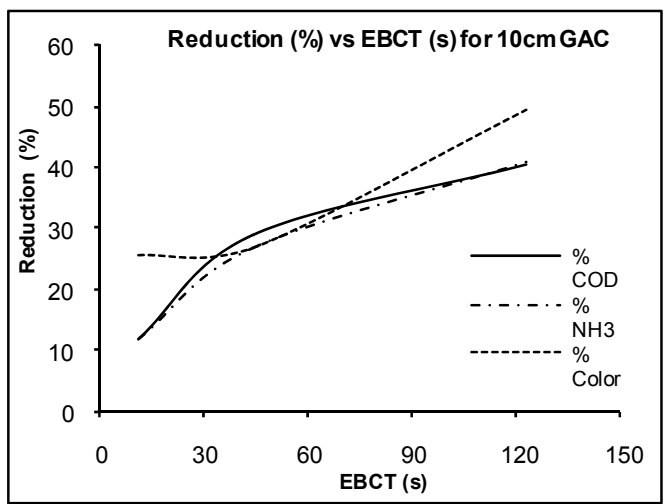

(c)

Figure 6. Removal efficiency of COD, ammonia and color in dye wastewater using (a) $6 \mathrm{~cm}$ (b) $8 \mathrm{~cm}$ and (c) 10 $\mathrm{cm}$ GAC height at different contact time (EBCT)

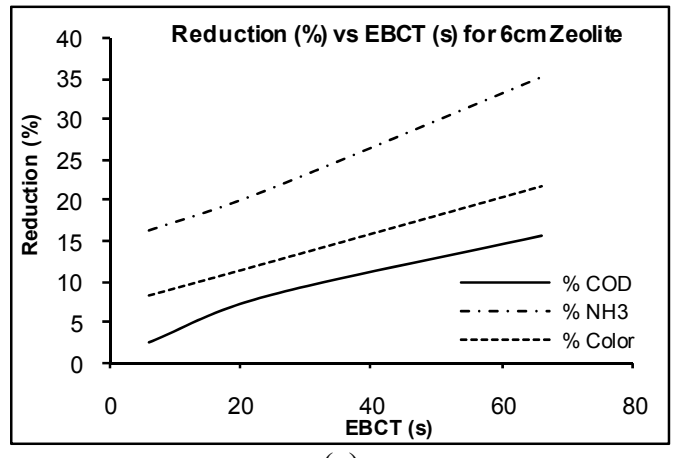

(a)

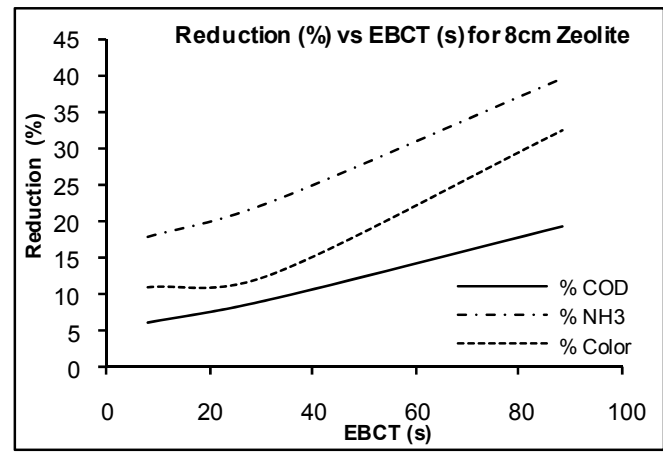

(b)

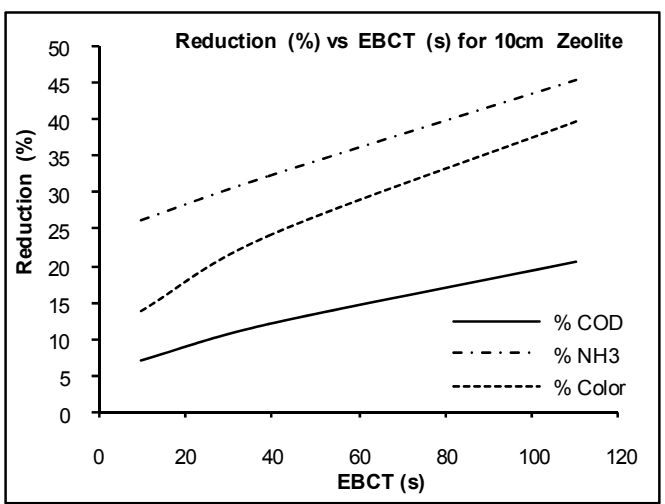

(c)

Figure 7. Removal efficiency of COD, ammonia and color in dye wastewater using (a) $6 \mathrm{~cm}$ (b) $8 \mathrm{~cm}$ and (c) 10 $\mathrm{cm}$ zeolite height at different contact time (EBCT) 


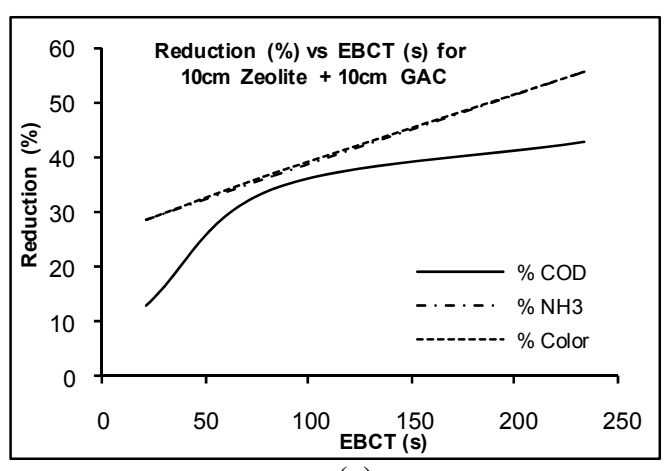

(a)

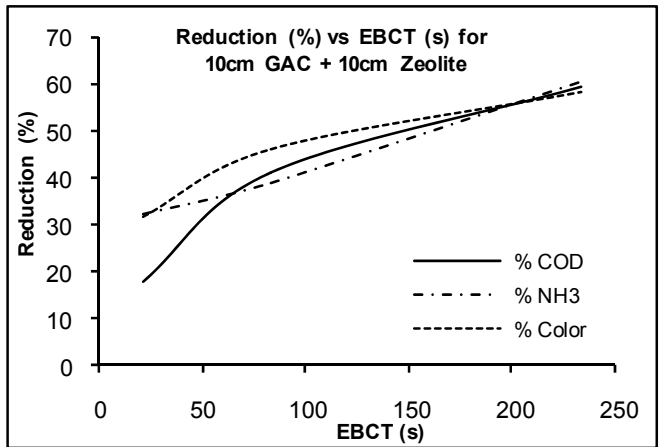

(b)

Figure 8. Removal efficiency of COD, ammonia and color in dye wastewater using (a) zeolite-GAC and (b) GAC-zeolite sequence arrangements at different contact time (EBCT)

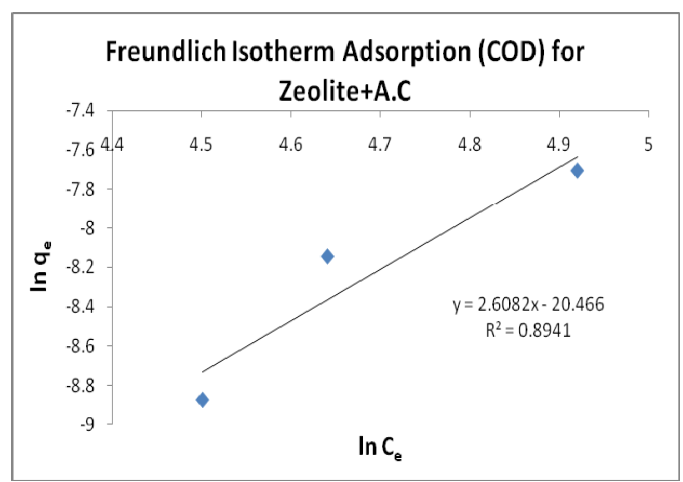

(a)

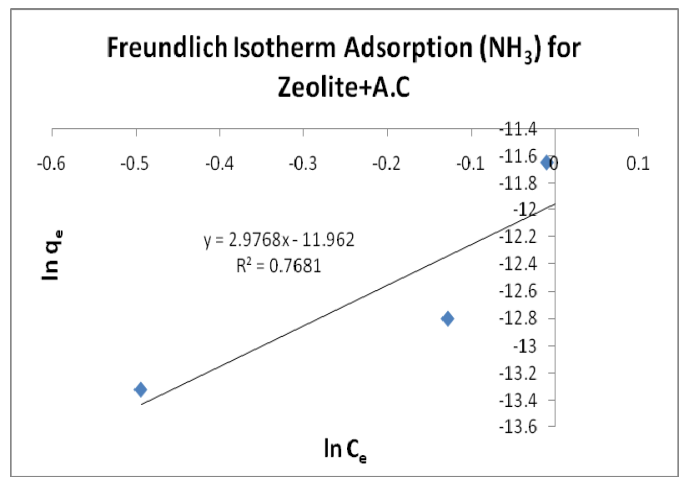

(b)

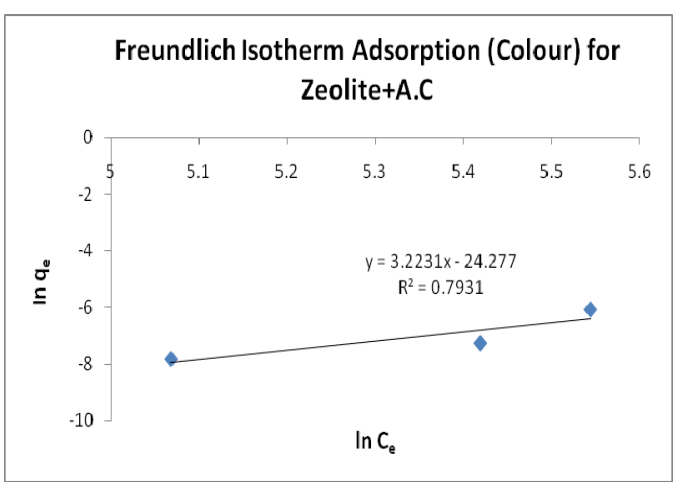

(c)

Figure 9. Freundlich isotherm for (a) COD, (b) ammonia and (c) color removal for dye wastewater treatment with zeolite as bottom layer and GAC as upper layer 


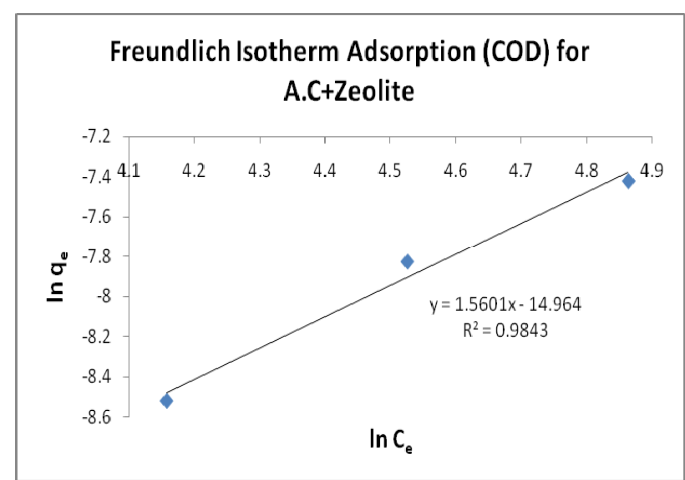

(a)

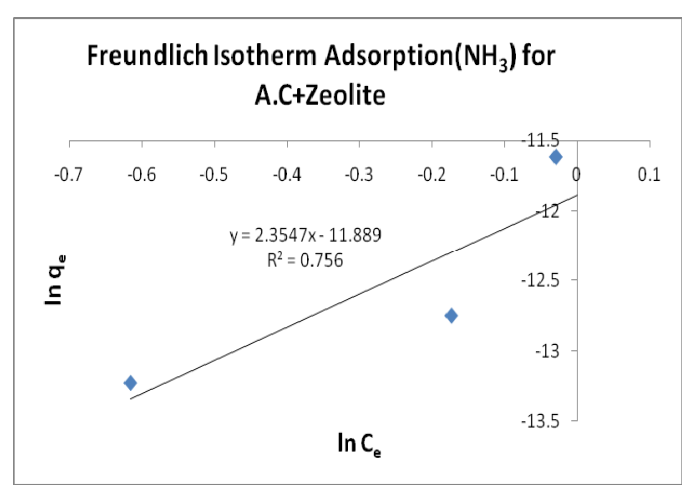

(b)

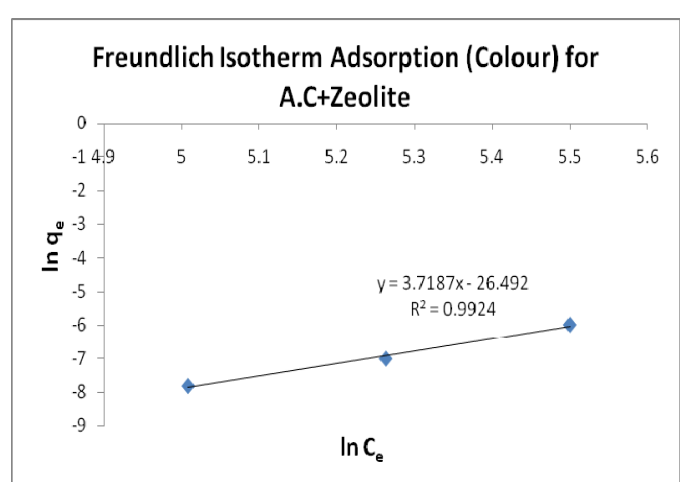

(c)

Figure 10. Freundlich isotherm for (a) COD, (b) ammonia and (c) color removal for dye wastewater treatment with GAC as bottom layer and zeolite as upper layer

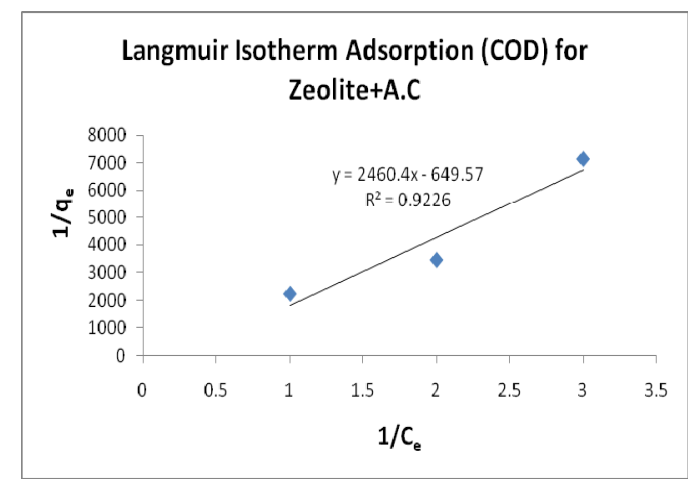

(a)

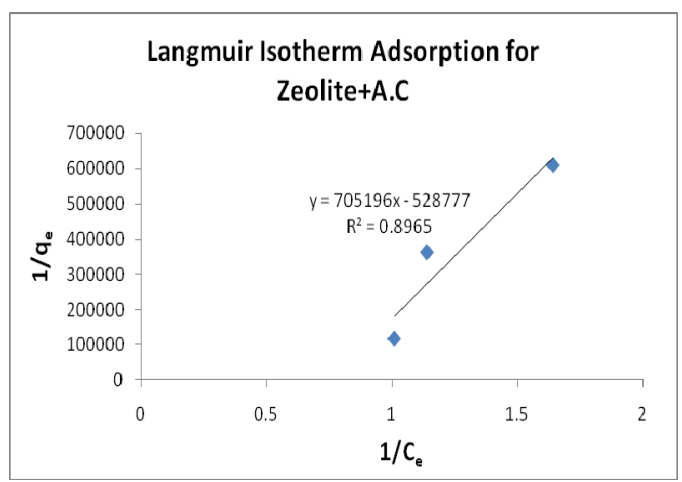

(b)

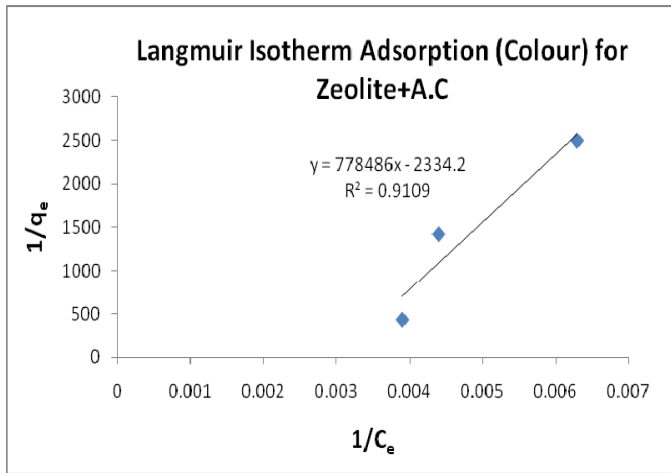

(c)

Figure 11. Langmuir isotherm for (a) COD, (b) ammonia and (c) color removal for dye wastewater treatment with zeolite as bottom layer and GAC as upper layer 


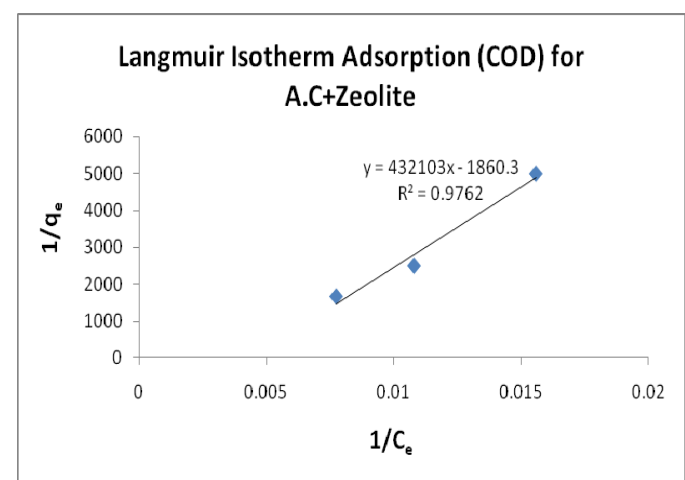

(a)

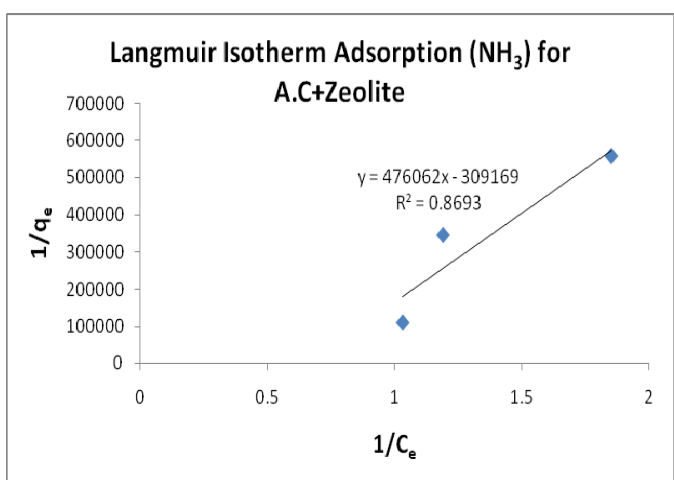

(b)

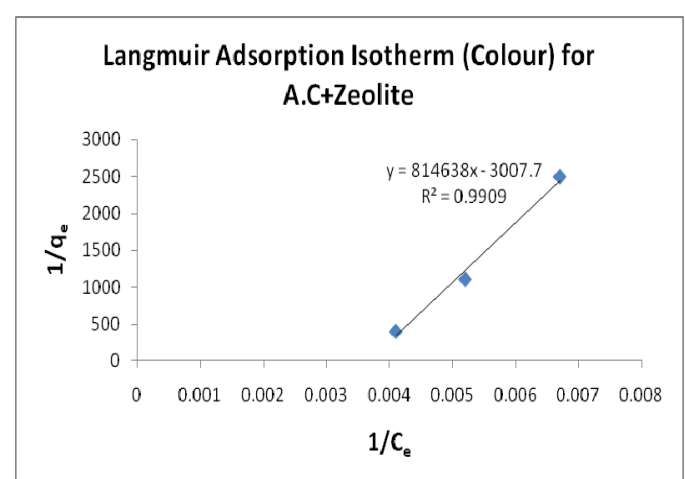

(c)

Figure 12. Langmuir isotherm for (a) COD, (b) ammonia and (c) color removal for dye wastewater treatment with GAC as bottom layer and zeolite as upper layer 